\title{
The school of the future: The WWW and learning processes in new learning environments
}

\author{
Betty Collis \\ Faculty of Educational Science and Technology, University of Twente,P.O.Box 217, \\ 7500 AE Enschede, The Netherlands. \\ Collis@edte.utwente.nl
}

\begin{abstract}
The IFIP WG 3.1 Chile 2000 Invitational Conference addresses the topic of the school of the future via four overlapping themes. The WWW and Webtechnologies can have a key role in one of these themes: learning processes and new learning environments. This key role will be explored by using a reference matrix that involves two main dimensions: a dimension relating to the location and ownership of learning resources, and a dimension relating to the difference between the WWW as library or marketplace and the WWW as workspace for learners to create and share resources. The impact of the WWW in the school of the future in relation to learning processes will be predicted and examples given of how this impact is already occurring will be described.
\end{abstract}

Keywords: Web-based systems, Web-resources, pedagogy, learner-centered learning

\section{INTRODUCTION}

The WWW, or the World Wide Web, the Web, websites, have become commonplace terms in society, so certainly they will be familiar terms in the school of the future. But familiarity does not necessarily mean centrality; the examples of the telephone and television attest to the fact that some technologies that are central to everyday life rarely become central to the core functioning of the school, in the classroom and in the direct teaching and learning process. Will this also be the case with the WWW?

The original version of this chapter was revised: The copyright line was incorrect. This has been corrected. The Erratum to this chapter is available at DOI: 10.1007/978-0-387-35403-3_29 


\section{THE USE OF THE WWW IN THE SCHOOL}

Before addressing this question, it is useful to make some clarifications about technology. There are many distinctions about Web-technology that are important to the school of the future. The most important may be:

- the distinctions among external websites, an internal intranet system, and a personal website;

- the distinction between using the WWW to find and interact with information or resources put there by others and using Web-technology to publish one's own information and artifacts or as a workspace;

- the distinctions among the different types of communication that can be supported by the WWW.

The first point is important to mention because sometimes it is assumed that the WWW has little application for schools because of the technical problems and high costs associated with accessing the WWW via the Internet as well as the social issues resulting from allowing children to be exposed to inappropriate external sites. An intranet system offers full Webfunctionality but does not have to involve making use of the Internet, or can control this access. All that is needed for a Web-based system running as an intranet is a local-area network in the school and one computer designated as a server. In addition, individual webpages can be made and used as standalone files without needing any network connection at all. Such files that can be copied via floppy disks and thus shared with others in a local environment, again without needing a network connection. In the discussion that follows about the potential role of the WWW and Web-technologies in the school of the future, there will be made a regular distinction between externally available WWW sites and resources, intranet systems, and individual websites and pages. Each has its potential contribution to the school of the future.

The second point, if one thinks of the WWW as an external repository which can be browsed and from which items can be selected, or if one sees the Web as a working environment via which new materials are developed and made available, has critical implications for the role of the WWW in the school of the future. The WWW as a library, or increasingly, as a marketplace, brings up different issues than those that pertain if the Web is primarily used as a working space. As a metaphor, it is the difference between giving a learner access to a library with a skilled librarian to steer him to find things efficiently, or giving the learner his own word processor and printer along with tools that facilitate his working together with others on the production of some sort of document. The different issues involved with the WWW as marketplace and the Web as working space are important for the school of the future. 
The third point relates to the number of persons receiving a communication (none, one, designated group, anyone), the degree to which the communicator knows those who will receive her messages and those who respond to her messages, the reusability of the messages, the structure of the messages (formal, structured, informal, non-structured), procedures relating to initiating a message, the use of text, audio, video, images, or some combination of each of these for communication and the intention of the messages (initiating a question, giving feedback, stating an opinion, giving an instruction). The degree and manner in which Web-functionality's are used to support different aspects of communication will affect the nature of the impact of the WWW in the school of the future.

\section{A GRID FOR WEB USE IN THE SCHOOL}

The first two of these points can be used to form a form a reference grid for Web-use in the school of the future, as shown in Table 1 where the columns relate to location and ownership and the rows relate to the marketplace/working space distinction. Numbers are given to the cells for convenient referencing in the subsequent discussion. Within each of the cells of the grid, different forms of communication can occur.

Table 1. Reference grid for WWW use in the school

\begin{tabular}{|l|l|l|l|}
\hline & External websites & Intranet system & Individual sites \\
\hline $\begin{array}{l}\text { USE RESOURCES OF } \\
\text { OTHERS }\end{array}$ & 1. & 2. & 3. \\
\hline CREATE RESOURCES & 4. & 5. & 6. \\
\hline
\end{tabular}

This grid can help us in the analysis of the role of the WWW in the school of the future in relation to the learning process and new learning environments. If we look from a learner's perspective Table 1 can be filled in as shown in Table 2 . 
Table 2. Characteristic activities relating to learning processes

\begin{tabular}{|l|l|l|l|}
\hline & External Websites & Intranet system & $\begin{array}{l}\text { Individual pages or } \\
\text { sites }\end{array}$ \\
\hline $\begin{array}{l}\text { USE RESOURCES } \\
\text { OF OTHERS }\end{array}$ & $\begin{array}{l}\text { 1. Can range from } \\
\text { library-type } \\
\text { reference use to } \\
\text { provision of } \\
\text { traditional computer- } \\
\text { based instruction. }\end{array}$ & $\begin{array}{l}\text { 2. Generally the } \\
\text { same as Cell 1, } \\
\text { except that the } \\
\text { source of what is in } \\
\text { the system is local. }\end{array}$ & $\begin{array}{l}\text { 3. Limited access } \\
\text { and distribution, as } \\
\text { has been the case } \\
\text { with traditional } \\
\text { computer-based } \\
\text { resources. }\end{array}$ \\
\hline $\begin{array}{l}\text { CREATE } \\
\text { RESOURCES }\end{array}$ & $\begin{array}{l}\text { 4. Can be used as a } \\
\text { reference source for } \\
\text { what is being } \\
\text { created, also as a } \\
\text { publication medium. }\end{array}$ & $\begin{array}{l}\text { 5. Same as Cell 4, } \\
\text { but what is created } \\
\text { can be labeled and } \\
\text { integrated with other } \\
\text { resources; access can } \\
\text { be controlled. }\end{array}$ & $\begin{array}{l}\text { 6. Learner uses the } \\
\text { WWW pages as a } \\
\text { medium for personal } \\
\text { expression; later } \\
\text { they can be shared. }\end{array}$ \\
\hline
\end{tabular}

\subsection{Using resources of others}

The strength of using external websites as sources of information is the fact of the vast quantities of information available, sometimes information that is not only timely but beyond what could be possible to obtain from a school library or textbooks. In addition, the use of external websites as sources of information sometimes allows direct communication with the person supplying the information, or with others interested in the information, highly unlikely to occur with non-WWW-resources originating outside of the local context of the learner. Counteracting these benefits is the difficulty of finding appropriate information. Copyright and cost issues, inefficient information-handling skills (inefficient skills in finding, evaluating the appropriateness of, and making use of information in terms of copyright and citations), and also the lack of quality control and cultural and language control of information in externally available websites will increasingly limit the amount of appropriate resources that learners are able to obtain from such sites. However, the use of the WWW for information will be a common, recurring activity in society as a whole; learners must develop these skills, not be sheltered from them. Intranet systems increase the chance that information will be appropriate, but at the cost of only offering a limited amount of information. Also, the information must be created or placed into the intranet (see Cell 5), a task that will require substantial time and effort at the local level.

In terms of hoping to find appropriate structured learning materials (in the sense of tutorials or other forms of teacher-independent materials), external websites are less likely to be of value, at least at the school level. The many variables that need to be aligned to the local situation of a learner 
before learning materials are appropriate for a learner are rarely going to be found in materials located on the Internet; tailoring of those materials by the teacher will need to occur (which then moves the activity into the second row of cells in the matrix in Table 2). As was the case with informational resources, structured learning materials available via a local Intranet will be much more likely to fit local conditions. But the time, skills and effort to create such materials will limit their realisation, just as it has limited the creation of computer-based learning materials by teachers for several decades. This is even more the case with standalone webpages, where access to a database of materials such as can occur with an intranet Web-system, cannot occur.

\subsection{Creating resources}

There is much more potential for new forms of learning activities when the focus is on using Web-functionality's to support the process of creating one's own resources. The emphasis shifts from (a) trying to find and supply just the right resource to (b) strengthening the learner's own communication and organisational skills. Resources as hyperlinks or externally obtained information can be incorporated into the materials being created, but are not the major focus of the learning experience; the process of creating one's own webpage or site as an exercise in reporting and communication is what is primary. If such a page or site is published on the Internet, if it is only available through an intranet, or even if it is only available as a local file, may not be important; this will depend on the learning context of what has been created. If children are creating reports to be shared with learners outside of those served by their Intranet, then publishing on the external WWW is a valuable motivation activity. But the majority of learnerproduced materials do not have meaning for the external world; their meaning is in the doing, and thus can be limited to Intranet or local-file sharing with others.

Web-based course-management systems are offering new ways for instructors and students to add learning resources that they create or tailor themselves to an Intranet system (Landon, 1998; Robson, 1999). These materials can be integrated with other resources and information relevant to a given course, class, or project; and can be used by other learners. New pedagogies are developing whereby learners are co-creators of learning materials for their peers or for other (Collis, Winnips and Moonen, 2000). Web-based course-management systems make it easy for learners to input such self-created learning materials into a website accessible to all their classmates, and to share and even add to such resources. Web-based tools can support learners working collaboratively on the creation of such 
resources; such tools are helpful even for learners who are working together in a face-to-face manner. Shifting learners into the role of co-producers of learning resources also is a response to the problem of locating materials for use in an Intranet system: let some of these be from the learners themselves.

\section{PREDICTIONS ABOUT LEARNING PROCESSES AND LEARNING ENVIRONMENTS}

Given the above, my predictions for the major impact of the WWW in the school of the future with respect to learning processes and learning environments are shown in Table 3.

Table 3. Predictions (given in italics within parentheses) about the impact of the WWW on learning processes and new learning environments

\begin{tabular}{|c|c|c|c|}
\hline & External websites & Intranet system & $\begin{array}{l}\text { Individual pages or } \\
\text { sites }\end{array}$ \\
\hline $\begin{array}{l}\text { USE RESOURCES } \\
\text { OF OTHERS }\end{array}$ & $\begin{array}{l}\text { 1. Can range from } \\
\text { library-type } \\
\text { reference use } \\
\text { (Common but } \\
\text { limited) to provision } \\
\text { of traditional } \\
\text { computer-based } \\
\text { instruction. }(\mathrm{No})\end{array}$ & $\begin{array}{l}\text { 2. Generally the } \\
\text { same as Cell } 1 \text {, } \\
\text { except that the } \\
\text { source of what is in } \\
\text { the system is local. } \\
\text { (Impact highest } \\
\text { when learners share } \\
\text { in the creation of the } \\
\text { resources to be used } \\
\text { by others, see Cell } \\
\text { 4.) }\end{array}$ & $\begin{array}{l}\text { 3. Limited } \\
\text { distribution, as with } \\
\text { traditional computer- } \\
\text { based resources }(\mathrm{No})\end{array}$ \\
\hline $\begin{array}{l}\text { CREATE } \\
\text { RESOURCES }\end{array}$ & $\begin{array}{l}\text { 4. Can be used as a } \\
\text { reference source for } \\
\text { what is being } \\
\text { created, also as a } \\
\text { publication medium } \\
\text { to make learners' } \\
\text { work available to the } \\
\text { external world. } \\
\text { (Common but } \\
\text { limited.) }\end{array}$ & $\begin{array}{l}\text { 5. Same as Cell } 4 \text {, } \\
\text { but what is created } \\
\text { can be labeled and } \\
\text { integrated with other } \\
\text { resources; access can } \\
\text { be controlled to } \\
\text { those within the } \\
\text { school or class. } \\
\text { (Impact can be } \\
\text { high.) }\end{array}$ & $\begin{array}{l}\text { 6. Learner uses the } \\
\text { WWW pages as a } \\
\text { medium for personal } \\
\text { expression; later } \\
\text { they can be shared. } \\
\text { (As HTML editors } \\
\text { are more common, } \\
\text { this becomes } \\
\text { relatively easy to do, } \\
\text { but publishing } \\
\text { requires WWW } \\
\text { server access or } \\
\text { intranet system.) }\end{array}$ \\
\hline
\end{tabular}

In terms of impact on the school of the future, this suggests a scenario where learners, of all ages, systematically learn search skills, skills in identifying appropriate information, and skills in how to properly make use 
of information produced by others. Learners and teachers will routinely look up information and resources via external websites, and if the information is about local situations, via an Intranet. How this information is used will depend on the teacher; it is not likely to be self-contained learning modules which replace the teacher even in an intranet system. Information-handling (finding, evaluating, selecting, using properly) literacy will be a major learning skill, relevant in different degrees in all subjects and at all grade levels. It must be learned in an incremental way, just as learners learn how to communicate. It will be part of the curriculum in the school of the future.

In terms of new learning processes, the use of a Web-based system with easy ways to upload learner-created resources offers the strongest potential, especially if learners can create such resources without having to learn a type of programming code, such as HTML, but only need to use editors (text, image, video, audio, HTML). At the least, learners have the experience of self-expression, but the potential is much stronger. Learners have new ways to work collaboratively on a complex document or multimedia product. Learners have new ways to share their work with others and to have their work become part of the study resources of the class. The process of communication is the focus, but it serves a double purpose, because what is produced as the result of this process can be a resource that can be studied by others. The problem of how to get adequate resources into an Intranet is addressed by using students as a source of some of these resources. The role of the teacher takes on a new dimension: that of guide and quality controller of learner production.

\section{EXAMPLES FROM PRACTICE}

At the University of Twente in The Netherlands, students in the Faculty of Educational Science and Technology are engaged in new learning processes using new learning environments in ways that illustrate the above predictions. Although these are university students, the pedagogical ideas involved can be scaled down for use with school-age students. Between 1994 and 1998, there was extensive use of the WWW in terms of Cell 6 in Table 2; via standalone sites created by pioneer instructors and used as environments to guide and support student activities. Most of these activities involved the students, working in groups, creating resources that were then evaluated by other students, all as part of the assessed learning processes in the courses (Collis, 1997; 1998). External websites were used for ideas and as links within the pages and sites made by the students (Cell 4 in Table 2). Because the faculty did not have a Web-based system available, all work was isolated and dependent on the technical skills of the instructor. Student- 
produced work had to go on the WWW in order for students to share each others' work, a situation that led to problems when external visitors to the course sites misinterpreted the work-in-progress aspects of the students' pages. The whole process was not likely to scale up to other instructors beyond the pioneers, as it was too labor-intensive for the instructor and required too much technical skill.

In 1998 the faculty moved from a pioneer-only approach in the use of the WWW to the use of a Web-based course-management system, called TeLeTOP (http://teletop.edte.utwente.nl). This Intranet is based on a set of design principles emphasising the need to make it easy for both instructors and students to create and input their own resources into a course website and the underlying database, and to share and reuse these materials (Tielemans and Collis, 1999). TeLeTOP is now being used by all instructors in the faculty, as well as in several other faculties. Underlying TeLeTOP there is an educational philosophy called C@mpus+ which has as major aspects the idea of students becoming more active and of gradually becoming professional in their behaviours. Thus new pedagogical ideas, supported by the new form of learning environment, the TeLeTOP system, are evolving at the faculty. Some examples of these are listed below.

\subsection{Students search external websites to select example and study materials for the course}

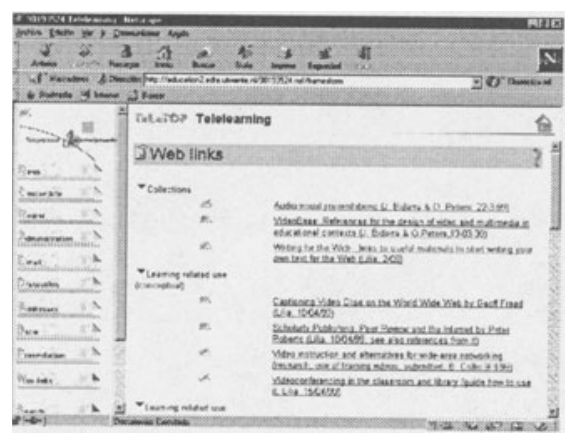

Figure 1. Weblinks

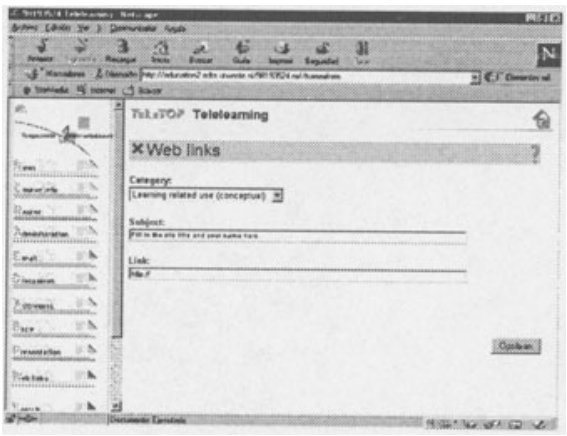

Figure 2. Fill-in form

In the course Tele-Learning the first assignment for the students is to locate examples of websites that are being used for certain types of educational purposes, and to enter these into a portion of the course website. These links are then used repeatedly throughout the course as a basis experiences and for students to compare and contrast in a number of subsequent assignments. The instructor reviews the choices made by the 
students and if not appropriate sends the student an e-mail explaining why and asking the student to delete the entry and upload a new one.

Figure 1 shows example materials added to a course environment, used subsequently by all students as examples and resources for the course.

Figure 2 shows the submission of such example materials to the course Web-environment simple via the use of a fill-in form which when submitted adds a copy of what was submitted to the course data base.

\subsection{Students create multiple-choice questions which are part of the resources for the course}

In the course General Psychology each student created two multiplechoice questions for each topic in the course and submitted these, along with comments relating to each of the four options offered for each question, into the course website. Students used a Web-based tool that was available via the Web-system for creating multiple-choice questions. The instructor checked the questions and only gave feedback when a question was weak in some respect. Students studied for the final examination of the course using the submitted questions as a resource. By the end of the course, over 600 questions for self-study were submitted into the database, and could be reused in subsequent years.

\subsection{Students create an instructional manual for subsequent classes}

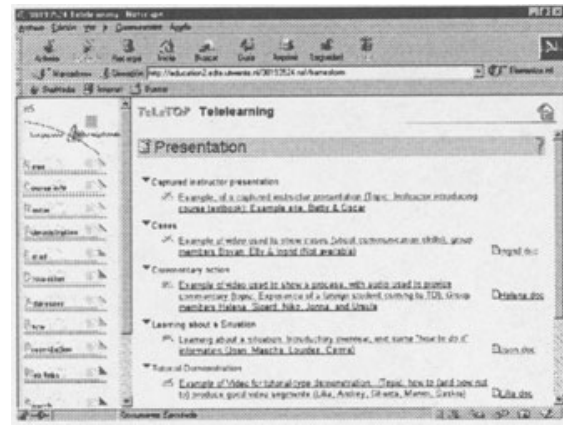

Figure 3. Presentation area

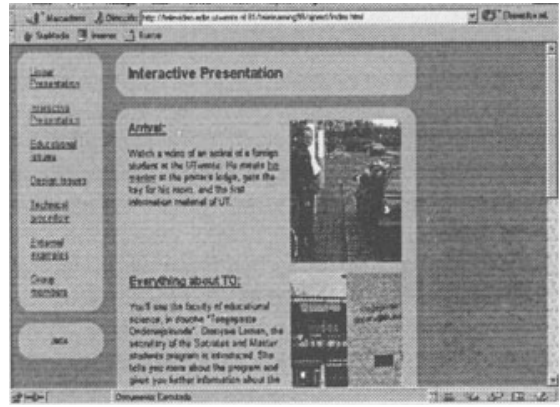

Figure 4. Menu of a manual

In the course Tele-Learning students work in groups to create a multimedia product, and then created an instructional manual based on what they had learned through their own experiences, to be used by subsequent 
groups of students doing the same assignment. The manual is available via the database system, and is linked to the final projects of the students.

Figure 3 shows the links to four of such instructional manuals added to the Presentation Area of a course website in the TeleTOP system. Figure 4 shows the menu page of one of these manuals, created as a Web-based resource making use of text, visuals, audio and video segments.

\subsection{Students create additional study resources}

In the course Instrumentation Theory 2 students work in groups of three, where each group focuses on one of the topics of the course, selects an article or articles to complement those already in the reader for the course on the chosen topic, and then prepares a document or website to summarise the new materials. When approved by the instructor, the new document or website is added to the course website, and becomes part of the study material for the course. The students also prepare a short video segment, explaining the main points in their new materials. These video segments are also uploaded into the course website and are meant to be used as additional support materials for the other students in the course. Figure 5 shows one of the Web-based reports integrated into the TeleTOP course website.

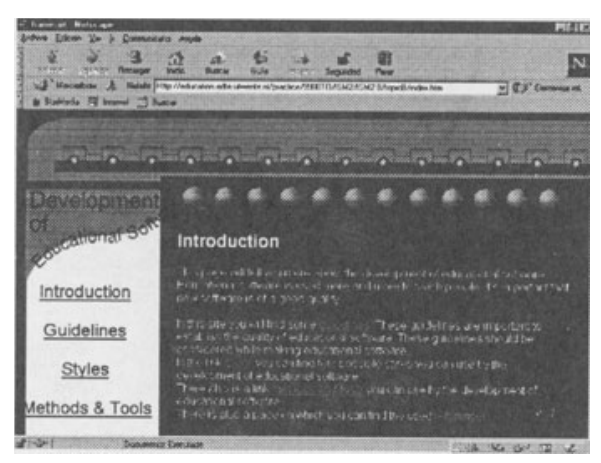

Figure 5. A Web-based report

\subsection{Students perform peer evaluations}

In a number of courses students use structured forms in the course website to provide formative evaluation of the work of other students, as well as for self-evaluation of their own work. There can be posed the questions to guide peer comments after a class presentation. Also the comments can be submitted via the course website by the end of the class 
period by students who were present at the presentations, and later, by students who were not present but could look at the class presentation materials via the website and add their comments later.

\subsection{Students take the responsibility for some of the lectures and associated study materials}

In the course Network Systems students work in groups. Each pair of groups is assigned to one of the lecture periods of the course. One group must prepare and deliver the lecture, making all support materials available via the course website. The other group must prepare a set of study questions based on the lecture, make these available via the website, and provide feedback as far as possible to the questions of students about these study questions. The instructor works closely with each group, to make sure the material presented is accurate and adequate.

In all the of above examples, the students are evaluated and graded on these activities. In this way, thousands of items with potential re-usability value as learning resources have been entered into the TeLeTOP database during its use to support the teaching and learning process. All of these items have been created by the instructors and students themselves. No special time, funding or training was required to produce the resources; in general, instructors only use a word processor or PowerPoint to create materials, while students also use HTML, image and video editors as well as word processors and PowerPoint. Entries can also be typed directly into the TeLeTOP system or copied and pasted in from a word processed document or a webpage. While the resources may vary in quality, based on external criteria, their primary value was in the process by which they were created, and as examples of student work and as extensions and supplements of the course study materials. It is not the case that these locally created items replace the textbook, but rather make the textbook dynamic. They share the benefit of fitting well with the local culture and context, as they were created within those. The TeLeTOP WWW-based course-management system supports Cells 2 and 5 of Table 2 and also allows access of external websites for ideas and links (for Cell 1 and Cell 4).

\section{CONCLUSIONS}

While the pedagogical strategy of learners being active and creating resources and sharing those with their classmates as part of the learning experience is not a new idea, the WWW and in particular a Web-based 
course-management Intranet allows possibilities that were not feasible before. The Intranet allows easy uploading, easy access by all classmates, easy reuse of learner-created resources, and can support group production of resources. Learners do not have to be at the same place at the same time to work together or to make use of each others' resources; all that learners (and teachers) need is a web browser and Intranet or Internet-access. Such ideas are relatively easy to realise technically, with access to a well-designed Web-based course-management system. The bottleneck will be not at the technical level, but at the human level. A number of barriers will confront a more regular use of learner-created resources.

\section{Norms}

Learners, parents, administrators, teachers all have deeply established views about learning resources; almost all of their experience has been to use materials made by "experts" and learn what is in them. The movement toward learning from each other raises the immediate fear that quality will be lost. Students themselves feel more comfortable mastering what is in a book than being told they have to extend what is in the book; students, parents, and administrators alike may argue that this uncertainly is not appropriate. Setting standards in advance for performance in a course becomes more difficult as students' work is taken seriously as study materials. Administrative procedures that require detailed specification of course content and evaluation criteria will not be compatible with an approach emphasising learner creation. The evaluation of the learning that occurs during the process of creating learning resources will be difficult to measure and grade.

\section{Time and effort}

It will take more time and work for both instructors and students alike as soon as learners move away from following a single prescribed textbook and doing assignments where all come up with the same, known-in-advance answers. As learners begin to locate their own supplemental study materials via external websites, the instructor must familiar him or herself with these materials, in order to guide the student as to the appropriateness of the choice. This can take much time, and require much time on-line, which may be very difficult for all involved. Students may complain that it takes too much time for them to find appropriate materials. More care must be taken with communication that is going to be used by others, not just submitted to the teacher. Communication skills for both learners and the teacher will be taxed in new and sometimes demanding ways. 


\section{Pedagogical creativity}

Reorienting one's instructional approach to an active-student perspective will not be easy for many teachers, partly because some will not find it easy to think of manageable activities that can fit the new approach. Because the tools are new, and the type of activities that make use of those tools are also new to them, many instructors will fail to think of educationally useful ways to engage students in new forms of process-oriented learning. Many examples are needed, and these need to evolve over a period of time.

In the TeleTOP system, instructors can easily visit each other's course environments to get ideas from each other. The matrix-like Roster is used in different ways by each instructor but makes it easy to see at a glance the instructional activities chosen for a particular class. Figure 6 shows part of a roster in one of the TeleTOP courses.

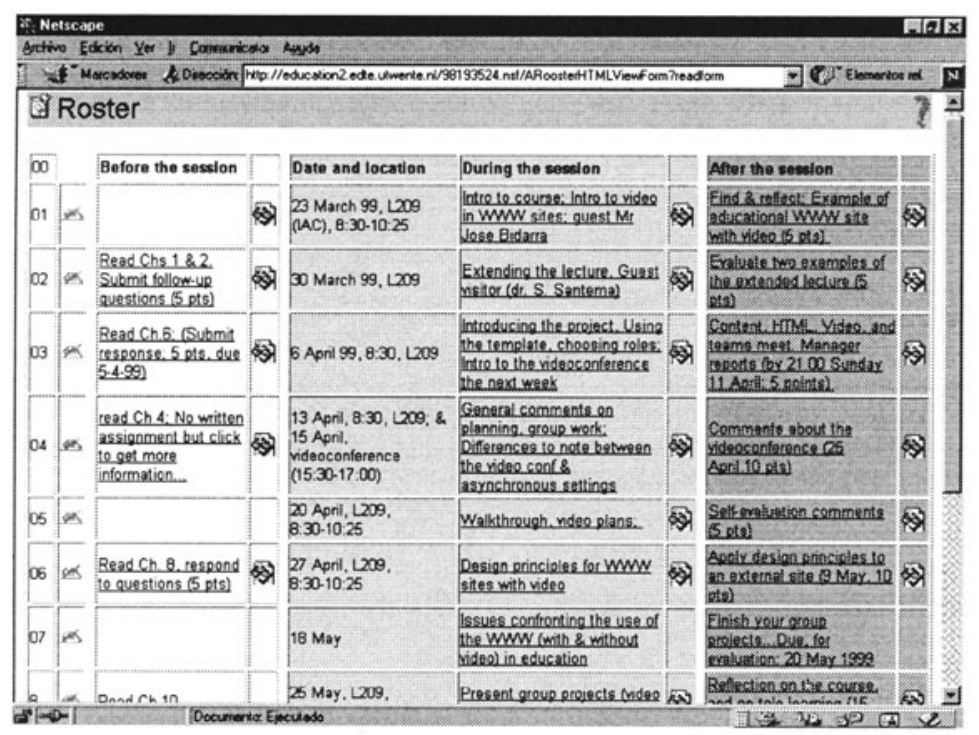

Figure 6. Part of the roster in one of the TeleTOP courses

Nonetheless, despite these possible constraints of local norms, time and effort, and the need for creativity, the use of Web-based tools and intranet systems offers so many possibilities for the school of the future that such tools and systems are likely to be part of the school even if not used to their full potential. These new learning environments will at the very least streamline various forms of communication and information handling. But because learners have the tools to communicate in many ways and to find and select resources from both external websites and an Intranet does not 
mean that they will do these things well. Doing them well requires good teaching and hard work on the part of the learners. In this respect, the school of the future with its use of the WWW will still resemble the school of the past and present.

\section{REFERENCES}

Collis, B. (1997) Pedagogical re-engineering: A new approach to course enrichment and redesign with the $W W W$, Educational Technology Review, 8, 11-15.

Collis, B. (1998) Building evaluation of collaborative learning into a WWW-based course: Pedagogical and technical experiences, Indian Journal of Open Learning, 7(1), 69-80.

Collis, B., Winnips, K., and Moonen, J. (2000) Scaffolding and the use of the WWW: Does it pay off?, Journal of Interactive Learning Research (in press).

Landon, B. (1998) Online educational delivery applications: A Web tool for comparative analysis. [http://www.ctt.bc.ca/landonline]

Robson, R. (1999) WWW-based course-support systems: The first generation, International Journal of Educational Telecommunications, (in press).

Tielemans, G., and Collis, B. (1999, 24 June) Strategic requirements for a system to generate and support $W W W$-based environments for a faculty, Paper presented at ED-MEDIA '99, Seattle.

\section{BIOGRAPHY}

Betty Collis is professor of Tele-Learning at the University of Twente in The Netherlands and also Chair of the TeleTOP Project. She has been working with WWW-based course-support sites since March 1994 and is thus a pioneer in this area. Prior to the WWW she has been involved in the use of computer-related technology for nearly two decades and has published an extensive amount in the area (see her home-site: http://users.edte.utwente.nl/collis/). Of particular current interest is the topic of instructors' reactions to possible uses of streaming video in WWW-based course support environments. 